\title{
Study on the Evaluation Mode in Air Conditioning Engineering and Practicums
}

\author{
Jian Chen ${ }^{1, a}$, Yijun Liü ${ }^{1, b}$ \\ ${ }^{1}$ College of Urban Construction, Wuhan University of Science and Technology, \\ Wuhan, P.R.China 430065 \\ achenjian@wust.edu.cn, ${ }^{\text {b } 524816786 @ q q . c o m}$
}

Keywords: production practice; graduation practice; air-conditioning engineering; evaluation mode

\begin{abstract}
Air Conditioning Engineering is a main professional theoretical course in the major of Building Environment and Energy Application Engineering, in practicums of which both production and graduation practice play an important role. Students' professional knowledge and virtue can be improved by the combination between theory and practice. The paper analyzes the evaluation mode in Air Conditioning Engineering and practicums, aiming at an enhancement of the assessment system by various modes.
\end{abstract}

\section{Introduction}

Air Conditioning Engineering is a main professional theoretical course in the major of Building Environment and Energy Application Engineering. Students should be equipped with the basic knowledge and basic skills in design, construction and operation management as well as the basic ability to resolve the practical problem in air conditioning engineering by studying the course. Meanwhile, students are expected to become senior applied talents in innovation and engineering practice. In addition, the education department has mention to attach importance to practicums and improve the students' practical ability. It's high time to reinforce practicums such as experiments, practice and production design[1].

\section{Choice of teaching material and teaching content}

The primary aim of Building Environment and Energy Application Engineering major is to cultivate innovative professional personnel with solid foundation who meet the registered public facility engineer qualification and international standards. For the purpose of teaching service for national construction, undertaking training of professional personnel, especially for the training of engineering application and technical service personnel, it's a must to choose a good textbook. The Air Conditioning Engineering chosen by our research office is a national planning material edited by Huang Xiang and published by the press of mechanical industry. This material has three characteristics:(1)Originally and fully reflects the new theory, standards as well as achievements, and pays attention to current national norms, standards, technical measures, especially the standard of national design registered equipment engineer professional qualification examination;(2)Practically focuses on the training of students' basic skills, provides students with essential knowledge of the air conditioning engineering design and application;(3)Considerably equips with questions and exercises after each unit[2].

This course is arranged with 40 lessons in the junior's second semester. To make a proper plan about the teaching content, it's favorable to avoid the repetition with other courses, such as load calculation in Building Environment and principle, process and equipment of air-conditioning in Fundamental and Equipment of Heat and Mass Transfer. The textbook is divided into tow parts. One is about the basic air conditioning systems, which are centralized air conditioning systems, semi-centralized air conditioning systems and distributed air conditioning systems. This is the crucial part that students need to master. The other part introduces several new air conditioning systems such 
as variable air volume system, air water radiant panel system, variable refrigerant volume system, household air conditioning system, heat pump air conditioning system, cool storage system, cold air distribution system and temperature \& humidity independent processed system[2,3].

\section{Evaluation mode of the theoretical course}

Conventional evaluation mode adopts examinations to assess how much students have acquired, with the fact that cheating occurs inevitably. In that case, it's hard to estimate the degree of students' acquisition. Specific circumstances such as the certain condition students may be in or whether the examination is comprehensive can also have a great influence on the results of the evaluation. Therefore, the evaluation, instead of being reckoned as the repetition of the content in the course, should not only reflects how much basic theories and skills that students have learned, but also shows how well the comprehensive ability in studying, analyzing and problem-solving that students have obtained.

The traditional teaching method and the teaching effect are not good. In order to make students participate in the classroom and enhance the interaction and fun, it's critical to let students know their domination place in the teaching process, so that they are aware of improving the learning and innovation ability as well as actively participating in the whole teaching process[4]. The author thinks teachers can take out a lesson for students to talk about, and then aim at the field that students are not well attained. This can not only get better results but also activate the classroom atmosphere and let the students gain knowledge.

Air Conditioning Engineering is characteristic of prodigious calculations, such as load calculation, air volume calculation, hydraulic calculation, air distribution calculation, etc. On the final of the course, there is a course design within 2 weeks. To reinforce the knowledge in students' mind, some calculations in the design are allocated into several coursework as a part of the assessment. Moreover, the building environment and energy application engineering office in our college has put more importance on air-conditioning so that students' production designs are mainly related to it. Hence, it's necessary to have more practice. As for the air volume calculation and energy calculation for a certain room, they can be arranged in assignments to assess the students' basic acquisition.

Regular examination is designed and estimated both by one teacher. As a result, students intend to ask the teacher for providing key points and limiting the range of examination, which only work for fast memory but not benefit students' acquisition and ability in analyzing and problem solving comprehensively. This issue can be avoided by separating the teaching and assessing as the two parts are done by different teachers, thus students are required to attain all they have learned. Additionally, as different teachers may hold different view on some problems, it's desirable to keep the question rigorous in an examination.

Traditional examinations generally have two invigilators who tend to walk around and whisper occasionally, which may have negative effects on students' thinking. Therefore, the author thinks that examination can implements the unmanned invigilation, and establish the integrity of the file record examination for students. In this case, apart from what teachers ask to bring, all that has nothing to do with the examination (such as mobile phones, etc.) is not allowed to be brought into the examination room. The Class should apply for it and be assessed whether is qualified to carry out it. Unmanned invigilation is a supreme honor evaluation for a class, which is given priority in terms of individual honor and class appraisal, etc. But if cheating is found, grades of whole class will be zero mark in the exam. This is related to each person's achievement and honor in the class, so teachers and cadres need to do ideological education of each student.

Table 1 result of assessment before and after

\begin{tabular}{ccc}
\hline class & 1102 class & 1202 class \\
\hline excellent and good rate(\%) & 47.1 & 59.3 \\
\hline failure rate(\%) & 2.9 & 0 \\
\hline average score & 78.3 & 81.2 \\
\hline
\end{tabular}


From table 1, we can know that the students' failure rate has dropped, at the same time that the excellent and good rate has been improved, and the average score is improved. The results are useful to carry out diversified assessment methods.

\section{Mode of production practice}

Production practice, an indispensable part of practicums, combines theory to practice. It's usually arranged by teachers in summer holidays for students. In this case, one place can be full of too much students while some students may not take it seriously. Fewer of them might even drop out, wasting a great chance to study. Therefore, our college decides to adopt these ways below to obtain more opportunities for students: (1) take full advantage of social resource to develop stable practice bases outside class; (2) make good use of teachers' network; (3) encourage students to use their weak ties to look for internship; (4) ask students to try online as there are also many enterprises offer chances; (5) improve the practice base on campus positively.

\section{Mode of graduation practice}

Graduation practice is another important part of practicums, usually arranged on the week three and four during the second semester in senior. Unlike production practice which lasts 2 months in a construction site or a designing institute, the graduation one includes visits in work sites and the genuine systems as well as lectures presented by engineers in work places during two weeks, which is obviously shorter than the former. As to the lectures, they firmly connect with the upcoming graduation design along with some new knowledge, thus broadening students' horizon. Furthermore, students should learn major-related codes, manuals, standards and drawings in the process.

\section{Evaluation mode of production practice}

As an element of practicums, the evaluation can help assess the performance of students, verify the effect of practice teaching and achieve the practicing goal. This can be an effective way to promote and enhance the teaching mechanism and measure the quality of talent cultivation. Conventional evaluation only focuses on the result while ignoring the process, to which we ought to attach more importance. Only combining both of them can lead students to pay much attention to their feelings in this practice so that to make great progress in the practice learning. Therefore, this practice evaluation involves the aspects below.

Attendance record sheet is used for noting students' attendance and discipline, which indicates students' attitude and performance. This part accounts for ten percent of all.

Students are required to take notes and record everything, among which the professional knowledge is mainly essential, such as systems and the function of equipment in them. Work journals serve as a complement of practice journals. This part accounts for ten percent of all.

After the practice, there is an examination including describing some system types seen in a construction site or plant and analyzing different forms of systems. Knowledge of professional courses, codes, manuals and standards are also involved. As for the types of question, multiple choices are dominated. Meanwhile, books are available in the examination. This part accounts for thirty percent of all.

Students have to complete the evaluation sheet covered with practice journals and a practice report, etc. after the practice. Practice journals are the records of students' daily work lives, an expression of the content, quality and attitude during the practice time. Practice report, the summary and suggestion of students, is about contents on arranged visits and lectures, new knowledge or problems, experience and reflection. What's more, it contains quality assessment of the training and tutors, satisfaction with the arrangement, advice on the existing problems and other specific expectations such as time and place during this practice[5]. Three thousands words are demanded at least. This part accounts for thirty percent of all. 
After checked about the evaluation sheets and work journals by tutors, students have to attend the defense within a week. The tutor of each student will ask questions regarding to some troubles on the scene and subsequent reflections. This part accounts for twenty percent of all.

\section{Conclusion}

Evaluation system of Building Environment and Energy Application Engineering is working on a diversified comprehensive way to make a good combination of theory courses and practicums. Carrying out various assessments can motivate the initiative and enthusiasm in students, thus fully exerting the encourage-oriented effect on the evaluation.

\section{References}

[1] Yiqun Tang. Journal of China Women’s University, 2014(6), p.120-124 (In Chinese)

[2] Xiang Huang. Air Conditioning Engineering (Machine Press, china 2013) (In Chinese)

[3] Li Tao, Junhua Chen. Heilongjiang Science and Technology Information, 2009(35), p.259 (In Chinese)

[4] Ziyun Wang. Refrigeration and Air Conditioning, 2010(2), p.71-73(In Chinese)

[5] Li Liu, Zhaolong Chen, Difan Zhang, Science and Technology Innovation Herald, 2014, p.190-191 (In Chinese) 